\title{
Chemical defense in the cave-dwelling millipede Brachydesmus troglobius Daday, 1889 (Diplopoda, Polydesmidae)
}

Slobodan E. Makarov ${ }^{1, *}$, Ljubodrag V. Vujisić ${ }^{2}$, Božidar P. M. Ćurčić ${ }^{3}$, Bojan S. Ilić ${ }^{4}$, Vele V. Tešević ${ }^{5}$, Vlatka E. Vajs ${ }^{6}$, Ivan M. Vučković ${ }^{7}$, Bojan M. Mitić ${ }^{8}$, Luka R. Lučić ${ }^{9}$, and Iris Ž. Đorđević ${ }^{10}$

\begin{abstract}
:
Makarov S.E. , VujisićL.V., Ćurčić B.P.M., IlićB.S., Tešević V.V., Vajs V.E., Vučković I.M., Mitić B.M., Lučić L.R. and Đorđević I.Ž. 2012. Chemical defense in the cave-dwelling millipede Brachydesmus troglobius Daday, 1889 (Diplopoda, Polydesmidae). International Journal of Speleology, 41(1), 95-100. Tampa, FL (USA). ISSN 0392-6672. http://dx.doi.org/10.5038/1827-806X.41.1.10

The troglomorphic millipede Brachydesmus troglobius Daday, 1889 (Polydesmida: Polydesmidae) secretes allomones from glands on both lateral surfaces of its body segments. The secretion was identified by gas chromatography-mass spectrometry (GC-MS) analysis with electron and chemical ionization, and was shown to be composed of a mixture of benzaldehyde, benzyl alcohol, benzoyInitrile, benzoic acid and mandelonitrile benzoate. Hydrogen cyanide was qualitatively identified by the picric acid test. This is the first identification of these compounds in a cave-dwelling polydesmid.
\end{abstract}

Keywords: Diplopoda; Brachydesmus; troglobitic; chemical defense; HCN

Received 12 August 2011; Revised 28 November 2011; Accepted 28 November 2011

${ }^{1}$ Institute of Zoology, Faculty of Biology, University of Belgrade, Studentski trg 16, 11000 Belgrade, Serbia (slobodan@bio.bg.ac.rs)

${ }^{2}$ Faculty of Chemistry, University of Belgrade, Studentski trg 12-16, 11000 Belgrade, Serbia (ljubaw@yahoo.com)

${ }^{3}$ Institute of Zoology, Faculty of Biology, University of Belgrade, Studentski trg 16, 11000 Belgrade, Serbia (bcurcic@bio.bg.ac. rs)

${ }^{4}$ Institute of Zoology, Faculty of Biology, University of Belgrade, Studentski trg 16, 11000 Belgrade, Serbia (bojan.ilic@bio.bg.ac. rs)

${ }^{5}$ Faculty of Chemistry, University of Belgrade, Studentski trg 12-16, 11000 Belgrade, Serbia (vtesevic@chem.bg.ac.rs)

${ }^{6}$ Institute of Chemistry, Technology and Metal- lurgy, University of Belgrade, Studentski trg 12-16, 11000 Bel- grade, Serbia (vvajs@chem.bg.ac.rs)

${ }^{7}$ Faculty of Chemistry, University of Belgrade, Studentski trg 12-16, 11000 Belgrade, Serbia (ivuckovic@chem.bg.ac.rs)

${ }^{8}$ Institute of Zoology, Faculty of Biology, Uni- versity of Belgrade, Studentski trg 16, 11000 Belgrade, Serbia (bojan@bio.bg.ac.rs)

9Institute of Zoology, Faculty of Biology University of Belgrade, Studentski trg 16, 11000 Belgrade, Serbia (luka@bio.bg.ac.rs)

${ }^{10}$ Faculty of Veterinary Medicine, University of Belgrade, Bulevar Oslobodjenja 18, 11000 Belgrade, Serbia (iris@vet.bg.ac.rs)

\section{INTRODUCTION}

Serbia is centrally located on the Balkan Peninsula and is characterized by the presence of numerous cave systems inhabited by endemic and relict cave animals belonging to different classes (Radoman, 1983; Pljakić, 1978, Ćurčić \& Decu, 2008). In the Carpatho-Balkan Mountains on the eastern part of Kučaj Mountaint, the Lazareva Pećina Cave (= Zlotska Pećina Cave), which possesses a very diverse underground life, is one of the most explored caves (Ćurčić et al., 1997). Ćurčić et al. (1997) noted that 20 species of invertebrates and 6 species of bats inhabit this cave system. Of this number, 13 invertebrate species are endemic either to the Carpatho-Balkanic Arch or to the Balkan Peninsula. Interestingly, 6 species of arthropods are endemic to the Lazareva Pećina Cave (Ćurčić et al., 1997). The same authors explain the variety of cavernicolous fauna in this cave to be the result of its long and complicated history, its origins having been largely affected by the diversity of the fauna inhabiting the Proto-Balkans in the remote past, as well as by the continuity of the continental phase in eastern Serbia, by the presence of thick limestone sediments, evolution of the underground karst relief, origin of numerous new niches in the subterranean milieu, and by the divergent differentiation of species in such isolated habitats. 


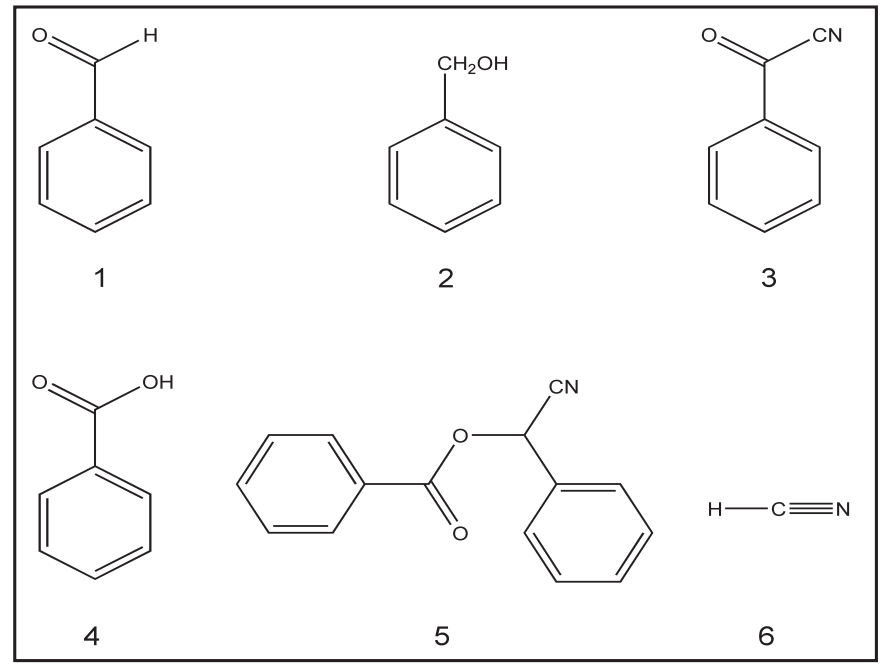

Figure 1. Structure of identified compounds from Brachydesmus troglobius Daday, 1889: 1 - benzaldehyde, 2 - benzyl alcohol, 3 - benzoylnitrile, 4 - benzoic acid, 5- mandelonitrile benzoate, 6 hydrogen cyanide. Compounds 1-5 identified from hexane extract by GC-FID and GC-MS, and compound 6 identified by picric acid test.

One of the typical cave-dwelling inhabitants in the Lazareva Pećina Cave is the millipede Brachydesmus troglobius Daday, 1889 (Fig. 3). This species is a true troglobite, inhabiting caves in Austria, Slovenia, Croatia, Montenegro, Hungary, and Serbia (Enghoff $\&$ Kime, 2010). The aims of this work were to the identify the chemical component in the defensive fluids in one cave-dwelling millipede; to test the possibility that adaptation to underground life has influenced the chemical defense mechanism; to compare the results on this species with previously analyzed surface-dwelling relatives, and to confirm cyanogenesis in polydesmids.

\section{MATERIAL AND METHOD}

Millipedes were collected during May 2010 in the Lazareva Pećina Cave, village Zlot, near Bor, eastern Serbia. The defensive secretions of ten females and ten males were extracted in hexane $(0.5 \mathrm{ml})$ for 3 min. To eliminate the effects of composition-altering oxidation and degradation of compounds, a portion of the extracts was analyzed by GC and GC-MS immediately after preparation.

Analyses were performed on an Agilent 7890A GC system equipped with 5975C inert XL EI/CI MSD and a FID detector connected by capillary flow technology 2-way splitter with make-up gas. An HP-5 MS capillary column (Agilent Technologies, $25 \mathrm{~mm}$ i.d., $30 \mathrm{~m}$ length, $0.25 \mu \mathrm{m}$ film thickness) was used. Samples were injected in splitless mode. The injection volume was $1 \mu \mathrm{l}$ and the injector temperature was $250^{\circ} \mathrm{C}$. The carrier gas $(\mathrm{He})$ flow rate was $1.3 \mathrm{ml} / \mathrm{min}$ at $40^{\circ} \mathrm{C}$ (constant pressure mode) while the column temperature was programmed linearly in a range of $40-300^{\circ} \mathrm{C}$ at a rate of $10^{\circ} \mathrm{C} / \mathrm{min}$ with an initial 1-min and final 8-min hold. The transfer line was heated at $280^{\circ} \mathrm{C}$. The FID detector temperature was $300^{\circ} \mathrm{C}$. Electron ionization mass spectra EI MS $(70$ $\mathrm{eV}$ ) were acquired in an $\mathrm{m} / \mathrm{z}$ range of 35-550. The ion source temperature was $230^{\circ} \mathrm{C}$ and the quadrupole temperature was $150^{\circ} \mathrm{C}$. Chemical ionization mass spectra CI MS (150eV) was obtained in positive mode with isobutane as reagent gas. The scan range was $\mathrm{m} / \mathrm{z}$ 60-550. The CI ion source temperature was $250^{\circ} \mathrm{C}$ and the quadrupole temperature was $150^{\circ} \mathrm{C}$.

A library search and mass spectral deconvolution and extraction were performed using NIST AMDIS (Automated Mass Spectral Deconvolution and Identification System) software, ver. 2.64. The retention indices were calculated from the retention times of

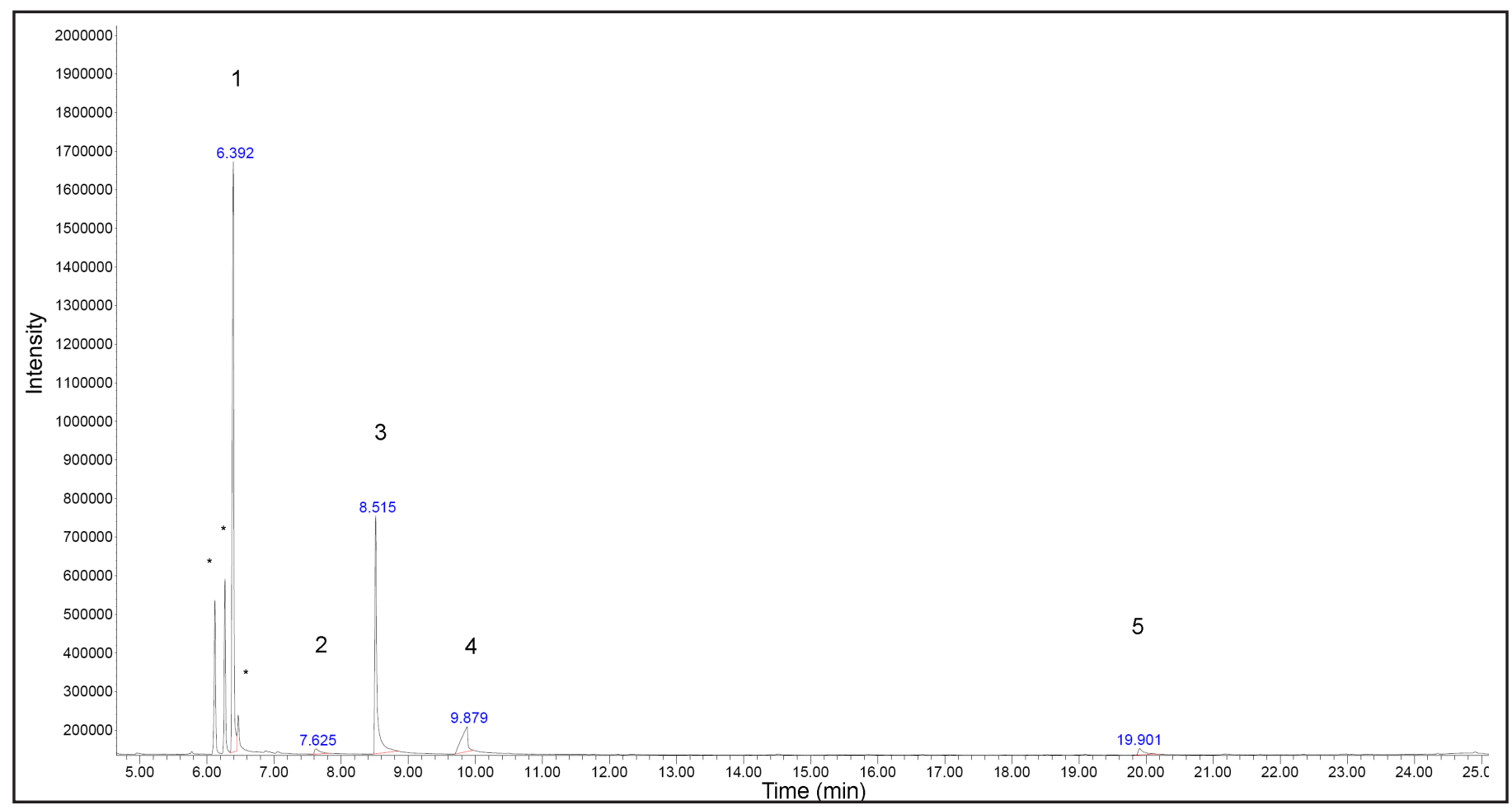

Fig. 2. GC-MS total ion chromatogram of hexane extract of Brachydesmus troglobius Daday, 1889. Peak 1: benzaldehyde; peak 2: benzyl alcohol; peak 3: benzoylnitrile; peak 4: benzoic acid; peak 5: mandelonitrile benzoate; *solvent impurities. 


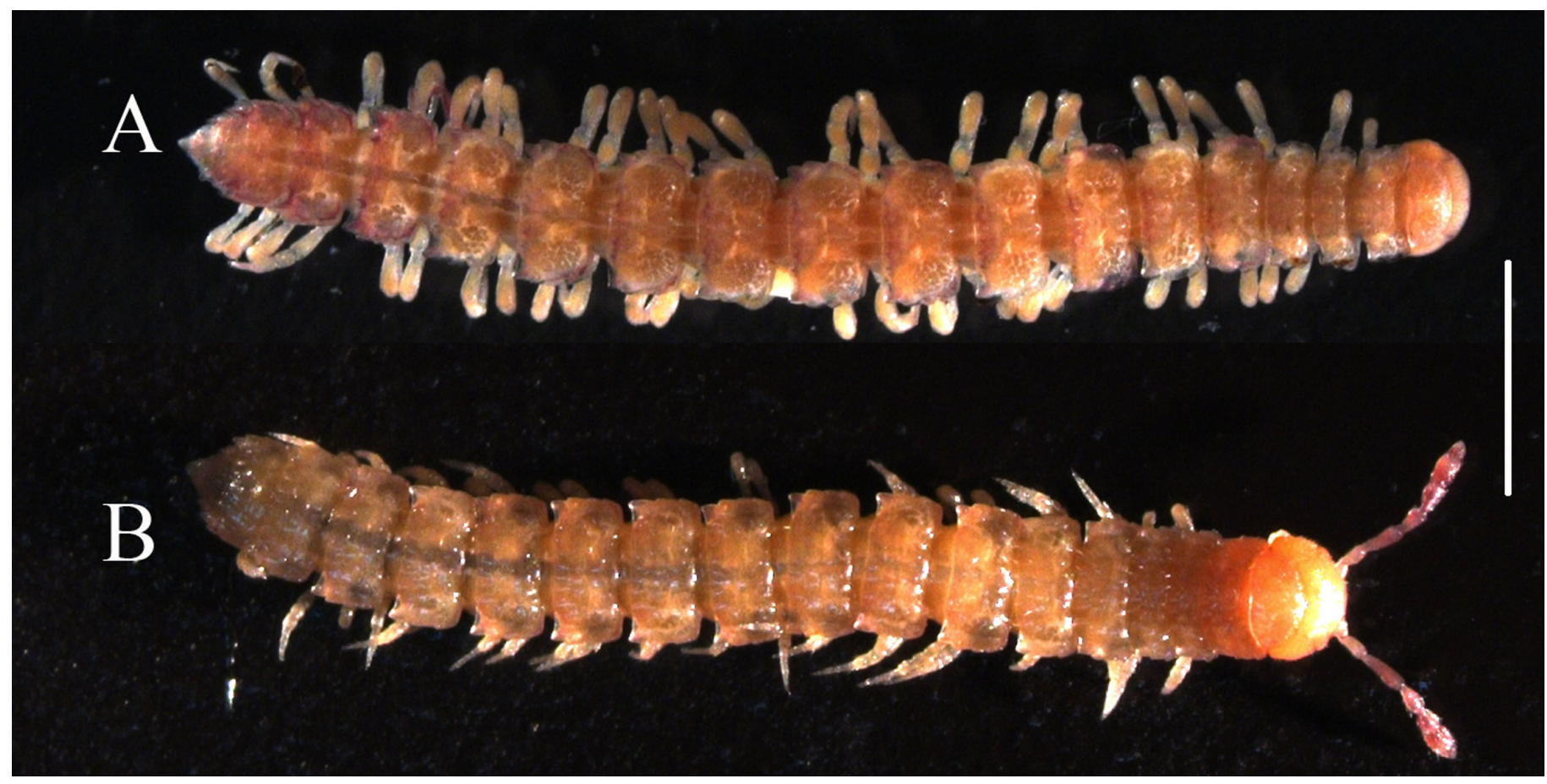

Fig. 3. Brachydesmus troglobius Daday, 1889 from the Lazareva Pećina Cave, village Zlot, near Bor, East Serbia. A - male, B - female. Scale line $=2 \mathrm{~mm}$.

$n$-alkanes which were injected after the sample under the same chromatographic conditions. The search was performed against our own library containing 4,951 spectra, and the commercially available Adams, NIST05 and Willey07 libraries containing more than 500,000 spectra.

The relative percentages of the identified compounds were computed from the corresponding GC-FID peak areas.

Hydrogen cyanide secreted from the live millipedes was qualitatively examined by the picric acid test. Filter paper, previously impregnated with a saturated solution of picric acid, was sprayed with $5 \%$ sodium bicarbonate. Live millipedes were placed onto the wet filter paper and squeezed forcefully (five specimens of each species). If the millipede secretions contained hydrogen cyanide, the color of the portion of the paper stained by the secretions gradually turned orange (Noguchi et al., 1997).

\section{RESULTS AND DISCUSSION}

Millipedes are known to produce chemical compounds against predators (Shear et al., 2007). The secretions include different quinones, phenolic compounds, organic acid, quinazolines, monoterpens, or cyanogenic compounds (Eisner et al., 1978). Chemical studies indicate that the quantitative and qualitative differences in millipede allomones show some phylogenetic patterns. For example, the production of hydrogen cyanide and other cyanogenic compounds is restricted to most of the representatives of the order Polydesmida (Omura et al., 2002a, 2002b; Taira et al., 2003; Shear et al., 2007). In these millipedes the predominant components are hydrogen cyanide and benzaldehyde, as well as phenol, benzoic acid, benzoylnitrile (= benzoyl cyanide) and mandelonitrile. Their profiles seem to be species-specific among Polydesmida. Furthermore, a recent study has shown that the composition of defensive fluids in some representatives of the family Polydesmidae indicate interspecific or intergeneric differences and that they may be useful in chemotaxonomy (Makarov et al., 2010). Hydrogen cyanide is a toxic component, believed to function as a defensive agent against predators (Zagrobelny et al., 2008).

Defense glands are present on somites 5,7 , $9,10,12,13$, and $15-18$ in $B$. troglobius. In these pleurotergites, the defense glands are located on the lateral sides on both paranotal expansions, as in many other polydesmids. The GC and GC-MS analyses of the hexane extracts in all specimens (male and female) of $B$. troglobius showed five volatile compounds: the major components were benzaldehyde (54.7\%) and benzoylnitrile $(30.7 \%)$; the minor ones were benzoic acid $(10.9 \%)$, mandelonitrile benzoate $(2.0 \%)$ and benzyl alcohol (1.7\%) (Table 1; Figs. 1 and 2). These compounds were identified by comparison of EI mass spectra in the NIST MS Search 2.0 computerized mass spectral libraries. The CI mass spectra of benzaldehyde, benzyl alcohol, benzoylnitrile, benzoic acid and mandelonitrile benzoate showed the presence of quasi-molecular ions at $\mathrm{m} / \mathrm{z} 107,109,132,123$ and 238 , respectively. In addition, hydrogen cyanide was detected with the picric acid test. No significant difference in the amounts of the components was observed between the sexes in the analyzed species.

Finding of the mandelonitrile benzoate is interesting in the light of recent papers of Kuwahara et al. (2011). These authors found that mandelonitrile benzoate is produced in large amounts together with hydrogen cyanide following shake-disturbances administered to several polydesmoid species. These species commonly produce mandelonitrile and benzoylnitrile. Species possessing no benzoylnitrile, such as Oxidus gracilis C. L. Koch and Cryptocorypha sp., could also produce mandelonitrile benzoate under conditions in which 


\begin{tabular}{cccc}
\hline Peak & $\mathrm{t}_{\mathrm{R}}(\mathrm{min})$ & Compound & $\begin{array}{c}\text { Relative } \\
\text { abundance }(\%)^{\mathrm{a}}\end{array}$ \\
\hline 1 & 6.39 & Benzaldehyde & 54.7 \\
2 & 7.63 & Benzyl alcohol & 1.7 \\
3 & 8.52 & Benzoylnitrile & 30.7 \\
4 & 9.88 & Benzoic acid & 10.9 \\
5 & 19.90 & Mandelonitrile benzoate & 2.0 \\
\hline
\end{tabular}

${ }^{a}$ Percentages calculated from GC-FID peak areas.

Table 1. Composition of the defensive secretions in Brachydesmus troglobius Daday, 1889 analyzed by GC-FID and GC-MS.

benzoylnitrile was exogenously provided. However, in $B$. troglobius (as in other analyzed species belonging to the genus Brachydesmus; Makarov et al., 2010) we could not found mandelonitrile, and it is difficult to include the analyzed species in either of the two groups of cyanogenic millipedes, as suggested by Kuwahara et al. (2011). On the other hand, the presence of mandelonitrile benzoate in defensive fluids may be the mechanism that stabilizes mandelonitrile if the specimen is consumed by a predator; in such cases this compound will be degraded during passage through the digestive tract, as proposed for some cyanogenic glucosides in Zygaena larva by Zagrobelny and Møller (2011).
The chemical composition of the defensive compounds in B. troglobius in comparison with its analyzed surface-dwelling relatives is interesting and indicative (Table 2). Makarov et al. (2010) showed that between the genera Polydesmus and Brachydesmus there exist differences in the chemical composition of the defensive secretion, including the presence of mandelonitrile only in the genus Polydesmus, and benzyl alcohol and benzoic acid only in the genus Brachydesmus. Our result confirms these findings. Mandelonitrile is absent and benzyl alcohol and benzoic acid are present in the whole body extract of $B$. troglobius. In addition, we confirm interspecific differences in defensive fluids within representatives of the genus Brachydesmus. The analyzed species differs from $B$. dadayi by the presence of benzoic acid (absent in B. dadayi), and from $B$. avalae by the absence of benzyl ethyl ketone (present in B. avalae).

Sher et al. (2007) have hypothesized that adaptive responses to local conditions are important in the evolution of the diplopod secretions which are employed by millipedes for defense against a variety of predators. Thus, it is not surprising that defensive secretions have evolved in response to local environmental conditions. Ćurčić \& Makarov (1998) showed that $B$. troglobius completed its life-cycle in the cave system (confirmed by the finding of all postembryonic stadia in cave). The selective pressure of predators in the Lazareva Pećina Cave is lower in comparison to surface habitats. It is comprised of several species of spiders, coleopterans, harvestmen,

\begin{tabular}{|c|c|c|c|c|c|c|c|c|c|c|c|c|c|c|c|c|}
\hline Compounds & 1 & 2 & 3 & 4 & 5 & 6 & 7 & 8 & 9 & 10 & 11 & 12 & 13 & 14 & 15 & Reference \\
\hline \multicolumn{17}{|l|}{ Species } \\
\hline Brachydesmus avalae Ćurčić \& Makarov & + & + & + & + & + & + & & + & & & & & & & & Makarov et al., 2010 \\
\hline Brachydesmus dadayi Verhoeff & + & + & + & & + & + & & + & & & & & & & & Makarov et al., 2010 \\
\hline Brachydesmus troglobius Daday & + & + & + & + & + & + & & & & & & & & & & Present study \\
\hline Polydesmus complanatus (Linnaeus) & + & & + & & + & + & + & + & + & & & & & & & Makarov et al., 2010 \\
\hline Polydesmus collaris collaris C. L. Koch & + & & & & & + & & & & & & & & & & Casnati et al., 1963 \\
\hline Polydesmus vicinus Saussure & & & & & & + & & & & + & & & & & & Casnati et al., 1963 \\
\hline Epanerchodus japonicus Carl & + & & & & & + & & & + & & + & & & & & Mori et al., 1994 \\
\hline Epanerchodus fulvus Haga & + & & + & & + & + & & & + & & & & & & & Kuwahara et al, 2011 \\
\hline Pseudopolydesmus erasus (Loomis) & + & & & & + & + & & & & & + & + & & & & Duffey et al., 1977 \\
\hline Pseudopolydesmus serratus (Say) & + & & + & + & + & + & & & + & & & & + & + & + & Conner et al., 1977 \\
\hline $\begin{array}{l}\text { Pseudopolydesmus canadensis } \\
\text { Newport }\end{array}$ & & & & & & + & & & & & & & & & & Eisner et al., 1975 \\
\hline
\end{tabular}

Table 2. Defensive secretion in the representatives of the family Polydesmidae. 1 - Benzaldehyde, 2 - Benzyl alcohol, 3 - Benzoylnitrile, 4 Benzoic acid, 5 - Mandelonitrile benzoate, 6 - HCN, 7 - Benzyl methyl ketone, 8 - Benzyl ethyl ketone, 9 - Mandelonitrile, 10 - Glucoside of p-isopropil mandelic nitrile, 11 - Phenol, 12 - Guaiacol, 13 - Myristic acid, 14 - Stearic acid, 15 - Isovaleric acid. 
and pseudoscorpions (Ćurčić et al., 1997). Also, it is well-known that adaptation to underground life includes certain morphological adaptations, such as the reduction of pigments and eyes, elongated appendages, the appearance of additional sensitive setae, as well as some physiological and behavioral changes (Romero, 2009; Culver \& Pipan, 2009). In accordance with these facts and the overall aspects of life in subterranean habitats, we expected that the number of allomones in the analyzed species could be lower or changed in comparison with surfacedwelling species. However, our finding does not confirm such a hypothesis. Instead it presents the chemical consistency of the defensive allomones, at least in polydesmid millipedes. It is as if this chemical defense mechanism has a high level of 'conservation' and that isolation, changes in selective pressure or colonization of a different habitat have not greatly affected its character.

Some findings point to a different role of the secretory compounds in $B$. troglobius. In a series of papers, Zagrobelny et al., (2008), Møller (2010), Zagrobelny \& Møller (2011), and Niels et al., (2011) analyzed the function of cyanogenic glucosides in plants and animals, and showed that they play several important roles in addition to defense in the life cycle of Zygaena filipendulae (Linnaeus, 1758). When ready for mating, the perching females emit plumes of HCN that may serve to attract flying males. The females prefer males that have a high content of cyanogenic glucosides, and during mating the male transfers a nuptial gift containing cyanogenic glucosides. In other insect species, males are also known to transfer seminal gifts containing bio-active natural products during mating (Møller, 2010). Furthermore, Bellairs et al. (1983) suggested that aggregations of the Indian polydesmoid Streptogonopus phipsoni (Pocock) were maintained by weak concentrations of benzaldehyde released from the repugnatorial glands. When alarmed, the quantity or concentration of the exudate rises and the swarm disperses. This results in a dilution effect and the swarm reaggregates when the concentration falls as pockets of the appropriate concentration are sought. Experiments were carried out on the reactions of the larvae to aquatic suspensions of benzaldehyde, since this substance is related to the components of the exudate of the repugnatorial glands; strong concentrations repelled the larvae, whilst weak concentrations attracted them. It is suggested that swarms may be dispersed or reaggregated by the effects of variations in the concentration of components of the exudates. Such a finding in both insects and diplopods indicates that in subterranean habitats, the secretory components found in $B$. troglobius may be useful in intraspecific communication, as alarm pheromones or as attractants during the mating process.

In conclusion, our results confirm cyanogenesis in the family Polydesmidae. They show that specificity in the chemical composition of defensive secretions could serve as criteria for millipede chemotaxonomy. They also reveal that adaptation to underground life has not led to a reduction or changes in the chemical defense mechanism, at least not in the analyzed B. troglobius.

\section{ACKNOWLEDGEMENTS}

This study was supported by the Ministry of Education and Science of Serbia (Grants Nos. 173038 and 172053). We wish to thank two anonymous referees for their helpful comments on the manuscript.

\section{REFERENCES}

Bellairs V., Bellairs R. \& Goels S., - 1983 Studies on an Indian polydesmoid millipede Streptogonopus phipsoni. Life cycle and swarming behaviour of the larvae. Journal of Zoology, 199: 31-50. http://dx.doi.org/10.1111/j.1469-7998.1983.tb06115.x

Casnati G., Nencini G., Quilico A., Pavan M., Ricca A. \& Salvatori T., 1963 - The secretion of the myriapod Polydesmus collaris collaris (Koch). Experientia, 19: 409-411. http://dx.doi.org/10.1007/BF02171516

Conner W.E., Jones T.H., EisnerT. \& Meinwald J., 1977 - Benzoyl cyanide in the defensive secretion of a polydesmoid millipede. Experientia, 33: 206-207. http://dx.doi.org/10.1007/BF02124069

Culver D.C. \& Pipan T., 2009 - The Biology of Caves and Other Subterranean Habitats. Oxford University Press, 254 p.

Ćurčić B.P.M., Dimitrijević R.N., Makarov S.E., Lučić L.R., Karamata O.S. \& Tomić V.T., 1997 - The Zlot Cave - a unique faunal refuge (Serbia, Yugoslavia). Archives of Biological Sciences, Belgrade, 49: 29P-30P.

Ćurčić B.P.M. \& Decu V., 2008 - Cave-dwelling invertebrates in Serbia. In: Makarov S.E. \& Dimitrijević R.N. (Eds.) - Advances in Arachnology and Developmental Biology. Papers dedicated to Prof. Dr. Božidar Ćurčić. Inst. Zool., Belgrade; BAS, Sofia; Fac. Life Sci., Vienna; SASA, Belgrade \& UNESCO MAB Serbia: 7-34.

Ćurčić B.P.M. \& Makarov S.E. - 1998 Postembryonic development in Brachydesmus troglobius Daday (Diplopoda: Polydesmidae) from Yugoslavia. Archives of Biological Sciences, Belgrade, 50: 9P-10P.

Duffey S.S., Blum M.S., Fales H.M., Evans, S.L., Roncardi R.W., Tiemann D.L. \& Nakagawa Y., 1977 - Benzoyl cyanide and mandelonitrile benzoate in the defensive secretions of millipedes. Journal of Chemical Ecology, 3: 101-113. http:/ / dx.doi.org/10.1007/BF00988137

Eisner H.E., Wood W.F. \& Eisner T., 1975 - Hydrogen cyanide production in North American and African polydesmoid millipeds. Psyche, 82: 20-23.

Eisner T., Alsop D., Hicks K. \& Meinwald J., 1978 - Defensive secretions of millipedes. In: Bettini S. (Ed.) - Arthropod Venoms. Berlin, Springer: 41-72.

Enghoff H., \& Kime R.D. (Eds.) 2010 - Fauna Europaea. Myriapoda. Fauna Europaea, version 2.4. Available from http://www.faunaeur.org

Kuwahara Y., Shimizu N. \& Tanabe T., 2011 Release of Hydrogen Cyanide via a Post-secretion Schotten-Baumann Reaction in Defensive Fluids of Polydesmoid Millipedes. Journal of Chemical Ecology, 37: 232-238. http://dx.doi.org/10.1007/s10886-011-9920-9 
Makarov S.E., Ćurčić B.P.M., Tešević V.V., Jadranin M.B., Vujisić Lj,V., Ćurčić S.B., Mandić B.M., Sekulić T.L. \& Mitić B.M.,. 2010 - Defensive Secretions in Three Species of Polydesmids (Diplopoda, Polydesmida, Polydesmidae). Journal of Chemical Ecology, 36: 978-982. http://dx.doi.org/10.1007/s10886-010-9847-6

Møller B.L., 2010 - Functional diversifications of cyanogenic glucosides. Current Opinion in Plant Biology, 13: 338-347.

Mori N., Kuwahara Y., Yoshida T. \& Nishida R., 1994 - Identification of benzaldehyde, phenol and mandelonitrile from Epanerchodus japonicus Carl (Polydesmida: Polydesmidae) as possible defense substances. Applied Entomology and Zoology, 29: 517-522.

Niels B.J., Zagrobelny M., Hjerno K., Olsen C.E., Houghton-Larsen J., Borch J., Møller B.L. \& Bak S., 2011 - Convergent evolution in biosynthesis of cyanogenic defense compounds in plants and insects. Nature Communications, 2 , http://dx.doi.org/10.1038/ncomms 1271

Noguchi S., Mori N., Higa Y. \& Kuwahara Y., 1997 - Identification of Nedyopus patrioticus patrioticus (Attems, 1898) (Polydesmida: Paradoxosomatidae) secretions as possible defense substances. Applied Entomology and Zoology, 32: 447-452.

Shear W.A., Jones T.H. \& Miras H.M., 2007 - A possible phylogenetic signal in millipede chemical defenses: The polydesmidan millipede Leonardesmus injucundus Shelley \& Shear secretes $p$-cresol and lacks a cyanogenic defense (Diplopoda, Polydesmida, Nearctodesmidae). Biochemical Systematics and Ecology, 35: 838-842. http://dx.doi.org/10.1016/j.bse.2007.01.005

Omura H., Kuwahara Y. \& Tanabe T., 2002a - 1-Octen3-ol together with geosmin: new secretion compounds from a polydesmid millipede, Niponia nodulosa. Journal of Chemical Ecology, 28: 2601-2612. http://dx.doi.org/10.1023/A:1021400606217
Omura H., Kuwahara Y. \& Tanabe T., 2002b Species-specific chemical composition of defense secretions from Parafontaria tonominea Attems and Riukiaria semicircularis semicircularis Takakuwa (Polydesmida: Xystodesmidae). Applied Entomology and Zoology, 37: 73-78. http://dx.doi.org/10.1303/aez.2002.73

Pljakić A.M., 1977 - Taksonomsko-biogeografskiodnosi primitivnih evolutivnih serija nižih Oniscoidea Jugoslavije posebno elemenata kavernikolne faune Srbije. Serbian Academy of Sciences and Arts, Special Edition, Belgrade, 184 p.

Radoman P., 1983 - Hydrobioidea, a superfamily of Prosobranchia (Gastropoda). I. Systematics. Serbian Academy of Sciences and Arts, Department of Sciences, Belgrade, $256 \mathrm{p}$.

Romero A., 2009 - Cave Biology. Life in Darkness. Cambridge University Press, 291p. http://dx.doi.org/10.1017/CBO9780511596841

Taira J., Nakamura K. \& Higa Y., 2003 - Identification of secretory compounds from the millipede, Oxidus gracilis C. L. Koch (Polydesmida: Paradoxosomatidae) and their variation in different habitats. Applied Entomology and Zoology, 38: 401-404. http://dx.doi.org/10.1303/aez.2003.401

Zagrobelny M. \& Møller B.L., 2011 - Cyanogenic glucosides in the biological warfare between plants and insect: The Burnet moth-Birdsfoot trefoil model system. Phytochemistry, 72: 1585-1592. http://dx.doi.org/10.1016/j.phytochem.2011.02.023

Zagrobelny M., Soren B. \& Møller B.L., 2008 - Cyanogenesis in plants and arthropods. Phytochemistry, 69: 1457-1468. http://dx.doi.org/10.1016/j.phytochem.2008.02.019 